\title{
Vasodilation secondary to exposure to galvanic currents
}

\author{
Margalef R. ${ }^{1} \quad$ Minaya Muñoz F. ${ }^{2} \quad$ Valera Garrido F. ${ }^{2} \quad$ Santafe M.M. ${ }^{1}$ \\ 1 Unit of Histology and Neurobiology, Department of Basic Medical \\ Sciences, Faculty of Medicine and Health Sciences, Rovira i Virgili \\ University, Reus, Spain \\ 2 Servicio de Fisioterapia MVClinic. Pozuelo de Alarcón, Madrid, Spain \\ Rev Fisioter Invasiva 2019;2:107.
}

\begin{abstract}
\section{Keywords}

- Galvanic currents

- percutaneous needle electrolysis

- dermis

- mouse

- image analysis

- mid to small caliber blood vessels.

Background The action of galvanic currents (GC) includes the generation of vasoactive substances such as, for example the vascular endothelial growth factor (VEGF) and its receptor, VEGFR-2.

Aim To evaluate modifications in blood flow by action of the galvanic current.

Material and Methods The experiments have been performed in Swiss male mice (4550 days old). The experiments were performed at controlled temperature and light settings. The hypodermis of the skin in the cranial area was used. The procedures were as follows: 1) A portion of skin was sectioned and lifted to obtain a control image; 2 ) the needle (Physio Invasiva $0.30 \times 40 \mathrm{~mm}$ ) was placed over the surface of the skull and covered with skin; 3 ) treatment was applied using $3 \mathrm{~mA}$, during 3 seconds and three applications (Physio Invasiva Prim); 4) the skin was immediately lifted once again and $3 \mathrm{~h}$ later to obtain experimental images. In the case of the controls, process 1-4 was repeated, however without applying current. The images were binarized (Digimizer 4.6.1. MedCalc Software) and the area occupied by the vessels of the same surface for each image.

Results In mice treated using the GC protocol $3 \mathrm{~mA}, 3$ seconds and 3 applications, an increase of $38.53 \% \pm 0.006$ was obtained immediately after the application of the GC. However, at three hours, this variation disappears (\% of variation: $4.03 \pm 0.01$ ), recovering control values. In the control experiments there was no modification.

Conclusions Galvanic currents provoke an immediate and transitory vasodilation in mid to small caliber vessels. An immediate and transitory vasodilation has two consequences: the arrival of cells responsible for the inflammatory reaction is accelerated (an essential and necessary step for the regeneration of tissues) and lavage of nociceptive substances is facilitated, which supports an analgesic effect.

\section{Acknowledgments}

The authors wish to thank the PRIM Physiotherapy company, who selflessly provided the needles and device to generate the Physio Invasiva ${ }^{\circledR}$ galvanic currents used in this study. This work is partially funded by a grant by Instituto de Salud Carlos III, Acción Estratégica en Salud (MMS, PI13 / 02084).
\end{abstract}

DOI https://doi.org/ 10.1055/s-0039-3401880. ISSN 2386-4591.
Copyright @ 2019 by Thieme Revinter Publicações Ltda, Rio de Janeiro, Brazil 